\title{
Development and Validation of a Scale Measuring Humanistic Professional Awareness for Healthcare Students and Providers
}

\author{
Hung-Chang Liao ${ }^{1,2}$ \\ Cheng-Yi Huang ${ }^{3,4}$ \\ Ya-huei Wang (D) 5,6 \\ 'Department of Health Policy and \\ Management, Chung Shan Medical \\ University, Taichung, Taiwan; \\ ${ }^{2}$ Department of Medical Management, \\ Chung Shan Medical University Hospital, \\ Taichung, Taiwan; ${ }^{3}$ School of Nursing, \\ Chung Shan Medical University, Taichung, \\ Taiwan; ${ }^{4}$ Department of Nursing, Chung \\ Shan Medical University Hospital, \\ Taichung, Taiwan; ${ }^{5}$ Department of \\ Applied Foreign Languages, Chung Shan \\ Medical University, Taichung, Taiwan; \\ ${ }^{6}$ Department of Medical Education, \\ Chung Shan Medical University Hospital, \\ Taichung, Taiwan
}

\begin{abstract}
Objective: This study aimed to develop an appropriate scale accessing healthcare students' and providers' humanistic professional awareness (HPAS-HSP).

Methods: Following a literature review, stakeholder interviews, and panel discussions for item generation, 65 items for the HPAS-HSP scale were created based on a nine-point Likert scale, with 9 indicating "strongly agree" and 1 indicating "strongly disagree." A pilot study using exploratory factor analysis (EFA) and confirmatory factor analysis (CFA), with seven hundred twenty-five medical care students and providers in Taiwan as the total sample number of the study, was administered to examine the practicability of the HPAS-HSP scale. The statistics software SPSS and AMOS 24.0 were used to examine the psychometric properties of the scale, including internal consistency, convergent validities, discriminant validities, and exploratory and confirmatory factor analysis.

Results: The EFA resulted in 21 items in three factors, with $66.221 \%$ of the total variance explained: "personal integrity and accountability" ( 9 items; $51.763 \%$ of the variance explained), "sensitivity to others" (6 items; $8.667 \%$ of the variance explained), and "medical professional competence" (6 items; 5.791\% of the variance explained). The Cronbach's alphas for the three subscales and the entire questionnaire ranged from 0.892 to 0.949 . The CFA results yielded 20 items, with the same three factors, and demonstrated good model fit in the $\chi^{2} / \mathrm{df}$ ratio $(1.130 ; p=0.140)$, CFI (0.998), TFI (0.998), and RMSEA (0.013). The composite alphas ranged between 0.900 and 0.969 . Convergent and discriminant validity also confirmed the stability and consistency of the scale.
\end{abstract}

Conclusion: The statistical results demonstrated that the HPAS-HSP scale can be a measure to assess healthcare students' and providers' humanistic professional awareness.

Keywords: humanistic professional awareness, healthcare students and providers, scale development, psychometric properties

\section{Introduction}

An overreliance on technology for problem solving has led to simplifications and routinization in medicine and has also led to a lack of sufficient reflection upon the essential humanitarian or humanistic professional qualities that healthcare professionals should possess. ${ }^{1}$ However, with the advance of patient-centered healthcare, a care focusing on not only physical comfort, but also the emotional well-being of patients and patient families, ${ }^{2}$ people have grown concerned about the overreliance on medical technology, observing that it dehumanizes healthcare, resulting in
Correspondence: Ya-huei Wang Department of Applied Foreign Languages, Chung Shan Medical University, Taichung, Taiwan Email yhuei@csmu.edu.tw 
patients, or even patient families, losing a personal connection with physicians and other healthcare professionals. Indeed, an awareness of patient empowerment has impelled healthcare professionals to refocus on humanism in medicine by addressing the spiritual and emotional needs of patients and patient families and, moreover, including them in healthcare decisions. ${ }^{3}$

Medical professionalism has been considered an essential foundation in medical education in order to optimize patients' health outcomes, ${ }^{4}$ and humanitarian qualities are also essential in medical practice. Certain similarities are clearly shared between the medical humanities and the healthcare profession, as both focus on medicine. However, there is a difference between professionalism and humanism: those with professionalism but without humanism just pretend to care. Although the term "medical humanities" is difficult to define, the core concepts of medical humanities, such as altruism, skill, and duty, are connected to the three fundamental principles of professionalism in medical practice: the primacy of patient welfare, patient autonomy, and social justice. ${ }^{5}$ In 1976, Moore, ${ }^{6}$ an Austrian physician, coined the term "medical humanities" to define what "doctorship" is from social, cultural, philosophical, and other perspectives. ${ }^{7}$ In order to restore humanity to the healthcare practice and allow students to reflect upon their roles as healthcare providers, medical humanities has become increasingly integrated into medical education. ${ }^{8}$

Coutts and Rogers ${ }^{9}$ proposed the $\mathrm{ABC}$ mnemonic (altruism, beneficence, and compassion) to remind physicians that, as humanitarian medical and healthcare professionals, in order to care for their patients, they should possess the following humanistic professional qualities: respecting patients' viewpoints and opinions; attending to patients' psychological well-being; regarding patients as individual beings; treating patients in their social, physical, and family contexts; facilitating a strong patient-healthcare provider relationship through good communication and listening skills; engendering trust and confidence; and demonstrating warmth, compassion, and empathy. In essence, to practice holistic medicine, healthcare providers should not only care about a patient's body, but also their mind, spirit, and emotions. ${ }^{10}$

Macnaughton ${ }^{11}$ declared that healthcare professionals should equip themselves with not only the knowledge of scientific medicine, but also the humanitarian qualities specific to medical care, which involves benevolence, compassion, courage, honesty, integrity, respect, and trust. ${ }^{12,13}$ Chou et $\mathrm{al}^{14}$ identified six attitudes for strengthening humanism: humanity, curiosity, standard of behavior, acknowledging the importance to treat patients medically and humanistically, acting humanistically, and treating more than just the disease. According to Cohen, ${ }^{15}$ professionalism refers to "a way of acting," entailing observable behaviors, while humanism refers to "a way of being," entailing personal commitment to others, especially those in need. Based on Cohen, ${ }^{15}$ those with humanistic qualities share the following attributes: altruism, compassion, duty, integrity, and respect. Indeed, those who have humanitarian qualities also have more insight into human conditions, such as human illness and suffering; hence, they are willing to provide more insight into medical and healthcare professionalism and responsibilities to both their patients and themselves. ${ }^{1}$ When patients are more satisfied with those possessing humanitarian and caring qualities, they will achieve better medical care outcomes. ${ }^{16}$

To instill authentic professionalism in healthcare practice, medical education should not only teach the expected professional behaviors, but also emphasize the cultivation of humanitarian values and attitudes. Hence, it is necessary to integrate humanism into healthcare professionalism in order to help students acquire correct humanistic behaviors and attitudes, thereby increasing their awareness of humanistic professionalism. ${ }^{17,18}$ Although research has shown that humanism can be taught and acquired via healthcare education, with difficulties in assessing humanism in healthcare, ${ }^{19}$ there is no specific or valid instrument which can be used to measure the humanistic professionalism in medical or healthcare education. ${ }^{20,21}$ Hence, in order to assess the feasibility of integrating humanism into healthcare education to increase students' humanistic professionalism, there is a necessity to develop an assessment to measure healthcare students' humanistic professional awareness. Thus, in order to cultivate medical humanities within healthcare students, an instrument must be developed to measure healthcare students' and providers' humanistic professional awareness and to establish relevant curricula, programs, courses, or on-the-job training to sharpen their humanistic professional awareness. To that end, this study aimed to develop a humanistic professional awareness scale for healthcare students and providers.

\section{Methodology Procedure and Participants}

In order to develop a feasible instrument measuring the awareness of humanistic professionalism, the intended Humanistic Professional Awareness Scale for Healthcare 
Students and Providers (HPAS-HSP) was developed, mainly based on Slavec and Drnovšek ${ }^{22}$ ten steps, divided into three phases (Phase 1, Steps 1-3; Phase 2, Steps 4-7; Phase 3, Steps 8-10). The ten steps were as follows: 1. a literature review and stakeholder interviews; 2 . item pool generation; 3. an expert panel to confirm the content validity; 4. scale development and assessment; 5 . scale translation into Mandarin Chinese and back-translation into English; 6. a pilot study; 7. sampling and data collection; 8. a dimensionality examination; 9. a reliability examination; and 10. a construct validity examination, including convergent validity and discriminant validity. The first phase (Steps 1-3) was associated with the theoretical framework and theoretical construction, the second phase (Steps 4-7) involved the representativeness and suitability of data collection, and the third phase (Steps 8-10) involved the statistical analysis and confirmation of the construct.

While conducting the research, the researchers followed the guidelines of the Research Ethics Framework of Society Institute in Taiwan. ${ }^{23}$ In addition, the study was reviewed and approved by the Institutional Review Board of Chung Shan Medical University Hospital (No. CS18216). Prior to study commencement, the informed consent was obtained from the research subjects. Before the data collection, the nature and purpose of the study were explained. Anonymity and confidentiality of identities and information were also assured. In addition, identities were kept strictly confidential, and personal information was anonymously analyzed. The initial developed scale was reviewed through a pilot study, with a sample of seven hundred twenty-five randomly selected medical care students and providers in Taiwan.

\section{Data Analysis}

The study used both EFA (exploratory factor analysis) and CFA (confirmatory factor analysis) to analyze the data. The researchers first used EFA via SPSS (version 14.0) ${ }^{24}$ to discover the underlying structure; the oblique rotation method was also used to minimize the number of factors. ${ }^{25}$ To validate the internal consistency of the HPAS-HSP scale, the researchers further applied CFA, using AMOS $24.0^{26}$ as a statistical method to examine the psychometric properties of the scale. In addition, the Kaiser-Meyer-Olkin (KMO) test $(>0.6),{ }^{27,28}$ Bartlett's test of sphericity $(p<0.05),{ }^{29}$ Cronbach alphas $(>0.7),{ }^{30}$ and goodness of fit indexes were used in the study. The goodness of fit indexes included $\chi^{2} /$ df ratio $(<2),{ }^{31}$ comparative fit index $(\mathrm{CFI} ;>0.90),{ }^{32,33}$
Tucker Lewis Index (TLI; > 0.90), ${ }^{34,35}$ and root mean square error of approximation (RMSEA; $<0.08) .{ }^{36}$

\section{Results \\ Using Slavec and Drnovšek's Ten Steps to Develop the HPAS-HSP}

As mentioned, the HPAS-HSP scale was developed, mainly based on Slavec and Drnovšek ${ }^{22}$ ten steps, divided into three phases. In Phase 1, the researchers conducted an extensive literature review and stakeholder interviews (Step 1) and hence initially collected 112 scale items (Step 2). After three runs of expert panel discussions (Step 3), with experts in the social sciences, instrument development, statistics, and medical education, the 112 items were reduced to 65 items. In Phase 2, the panel made an agreement that the HPAS-HSP scale was rated on a nine-point Likert scale, with 9 meaning "strongly agree" and 1 meaning "strongly disagree" (Step 4). The higher the HPAS-HSP score, the stronger the humanistic professional awareness a participant had. Once the scale items were reduced to 65 items, these items, initially developed in English, were translated into Mandarin Chinese and then translated back into English to confirm its content validity (Step 5). Also, to examine the psychometric properties of the construct, the researchers conducted a pilot study (Step 6) on seven hundred twentyfive healthcare students and professionals in Taiwan as the representative samples (Step 7) for data collection and for generalization. In Phase 3, after data collection, the study used EFA and CFA to assess dimensionality (Step 8) and calculated Cronbach's alpha values to examine the internal consistency of the HPAS-HSP scale (Step 9). Moreover, convergent validities, discriminant validities, and goodnessof-fit indexes were also calculated to assess the construct validity (Step 10). The more specific description regarding Phase 3 is illustrated as below.

\section{EFA Model for the HPAS-HSP Scale Kaiser-Meyer-Olkin (KMO) Test and Bartlett's Test of Sphericity}

Seven hundred twenty-five valid surveys were taken as a pilot study for data analysis. The study used the KMO test and Bartlett's test of sphericity to ensure sample adequacy and suitability of the data for factor analysis. Based on Kaiser, ${ }^{27,28} \mathrm{KMO}$ values below 0.50 are regarded as very poor, values between 0.50 and 0.59 are regarded as poor, $0.60-0.69$ are regarded as average, $0.70-0.79$ are considered good, $0.80-0.89$ are considered very good, and $0.90-1.00$ 


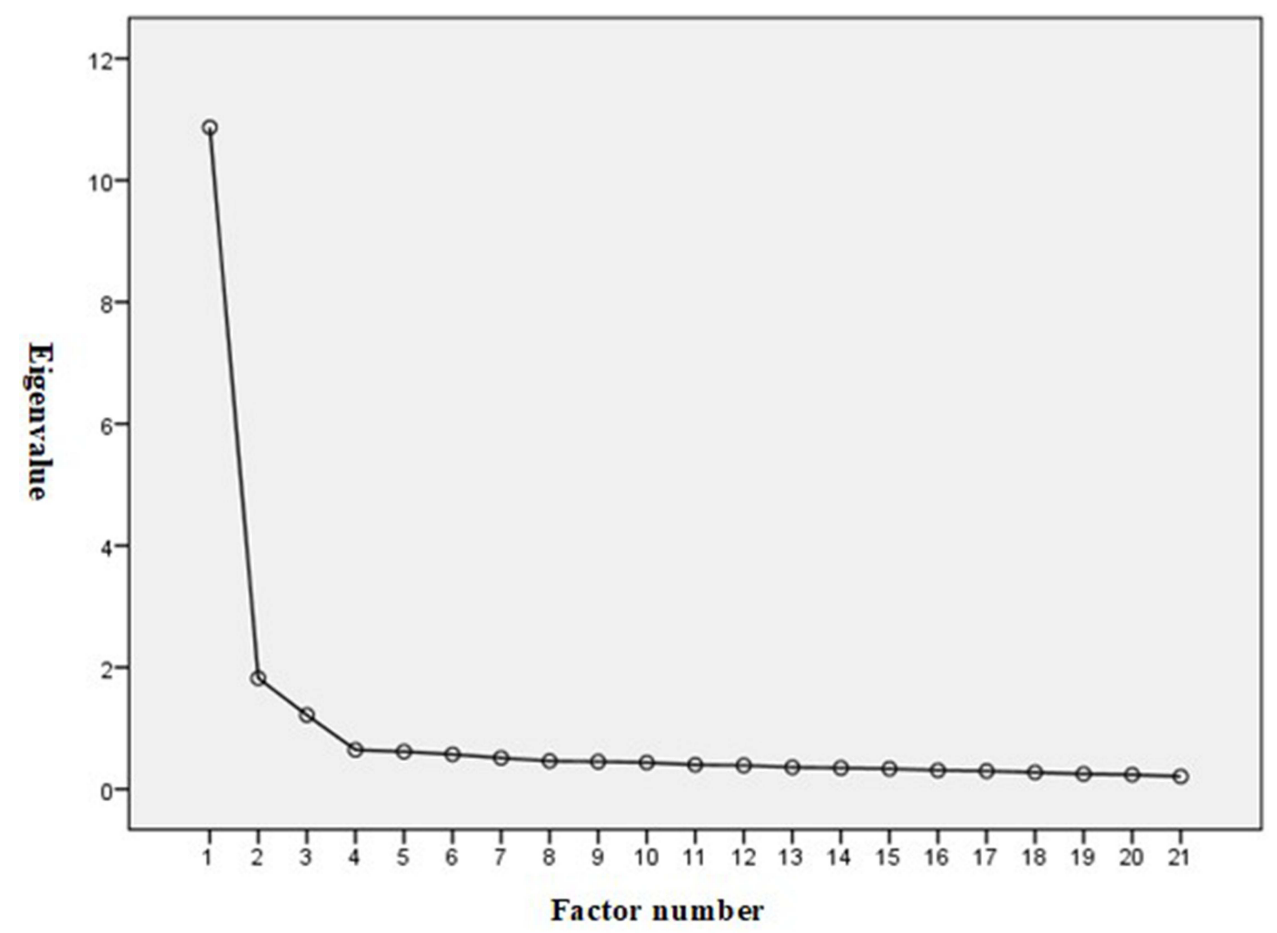

Figure I Principal component scree plot of HPAS-HP's factor structure.

are considered excellent. The KMO value derived in this study was 0.964 , higher than the benchmark of $0.6 .^{27}$ Bartlett $^{29}$ test of sphericity was highly significant, with a $p$ value less than 0.001 (approx. $=10,387.101$; degrees of freedom $=210 ; p$ value $=0.000<0.05$ ). The results of the KMO test and Bartlett's test proved the appropriateness of the sample size for EFA. The scree-plot for factor analysis of the HPAS-HSP also shows that optimum number of factors for the scale is three (see Figure 1).

\section{EFA for Principal Component Analysis}

EFA was adopted to examine the construct validity and internal consistency of the HPAS-HSP, using eigenvalues of 1.0 and principal component analysis with promax rotation. According to Hair et al, ${ }^{30}$ factor loadings between the absolute values of \pm 0.30 and \pm 0.40 explain a variable at the minimum level. Factor loadings with an absolute value of \pm 0.50 or greater significantly explain a variable. Factor loadings greater than the absolute value of \pm 0.70 are regarded as a well-defined factor structure to explain a variable. In this study, an item was retained when its loading was higher than absolute values of \pm 0.70 for relevant factors and lower than that of 0.70 for nonrelevant factors (see Table 1).

As previously mentioned, after the panel discussions, the 112 items were reduced to 65 items for the HPAS-HSP; after EFA, by using promax rotation for principal component analysis, 21 items and three factors were identified, with $66.221 \%$ of the total variance explained: "personal integrity and accountability," "sensitivity to others," and "medical professional competence." Factor 1 contained 9 items related to "personal integrity and accountability" and accounted for $51.763 \%$ of the variance explained. A sample item for factor 1 is "Medical professionals should strive to protect the rights and privacy of research participants." Factor 2 contained 6 items related to "sensitivity to others," accounting for $8.667 \%$ of the variance. A sample item for factor 2 is "Medical professionals should devote themselves to listening to patients' illness stories and empathizing with theirs pain and emotional reactions." Factor 3 contained 6 items pertaining to "medical professional competence," explaining $5.791 \%$ of the variance. The following is a sample item:

Medical professionals should be committed to continuous self-learning and professional development, demonstrating their lifelong learning ability to improve their medical competency.

All three factors from the principal component analysis have eigenvalues greater than 1: 10.870, 1.820, and 1.216 in "personal integrity and accountability," "sensitivity to others," and "medical professional competence," respectively (see Table 1). 
Table I Rotated Factor Loadings and Cronbach's Alphas for the HPAS-HSP

\begin{tabular}{|c|c|c|c|}
\hline Item & $\begin{array}{l}\text { Factor I: } \\
\text { Personal } \\
\text { Integrity } \\
\text { and } \\
\text { Accountability }\end{array}$ & $\begin{array}{l}\text { Factor 2: } \\
\text { Sensitivity } \\
\text { to Others }\end{array}$ & $\begin{array}{l}\text { Factor 3: } \\
\text { Medical } \\
\text { Professional } \\
\text { Competence }\end{array}$ \\
\hline \multicolumn{4}{|c|}{ Factor I: Personal Integrity and Accountability } \\
\hline 50 & 0.830 & & \\
\hline 59 & 0.803 & & \\
\hline 54 & 0.781 & & \\
\hline 43 & 0.744 & & \\
\hline 52 & 0.737 & & \\
\hline 49 & 0.736 & & \\
\hline 60 & 0.729 & & \\
\hline 55 & 0.727 & & \\
\hline 36 & 0.722 & & \\
\hline \multicolumn{4}{|c|}{ Factor 2: Sensitivity to Others } \\
\hline 24 & & 0.830 & \\
\hline 29 & & 0.806 & \\
\hline 22 & & 0.782 & \\
\hline 28 & & 0.778 & \\
\hline 16 & & 0.773 & \\
\hline 20 & & 0.749 & \\
\hline \multicolumn{4}{|c|}{ Factor 3: Medical Professional Competence } \\
\hline I & & & 0.825 \\
\hline 5 & & & 0.818 \\
\hline 4 & & & 0.761 \\
\hline 6 & & & 0.742 \\
\hline 3 & & & $0.74 I$ \\
\hline 2 & & & 0.735 \\
\hline Eigen value & 10.870 & 1.820 & 1.216 \\
\hline$\%$ of variance & 51.763 & 8.667 & 5.791 \\
\hline
\end{tabular}

Note: Total variance explained is $66.221 \%$.

Validity and Reliability Analysis of the EFA for the HPAS-HSP Scale

Initially developed in English, the scale was translated into Mandarin Chinese and then translated back into English; the two versions were reviewed and compared by bilingual teachers and experts to ensure content validity. Minor modifications were then made based on the reviewers' suggestions in order to avoid ambiguity of the item statements.

The researchers used Cronbach's alphas as a measure of internal consistency within each factor of the scale, taking 0.7 as the minimum criterion of reliability and 0.8 or greater as a better criterion. ${ }^{37}$ The results showed that the Cronbach's alpha values were $0.927,0.892$, and 0.904 for the three subscales "personal integrity and accountability," "sensitivity to others," and "medical professional competence," respectively; the Cronbach's alpha for the entire HPAS-HSP scale was 0.949 , demonstrating that the subscales and the overall HPAS-HSP scale have excellent reliabilities in measuring healthcare students' and providers' humanistic professional awareness (see Table 1).

Scale Item Statements, Item Mean Scores, and Standard Deviations

The HPAS-HSP's scale item descriptions, item mean scores, and standard deviations are shown in Table 2.

\section{CFA Model for the HPAS-HSP Scale}

After the EFA was conducted, the 65 items in the HPAS-HSP scale were reduced to 21 items in three factors; also, the construct validity and the internal consistency were confirmed. Then, through CFA, the researchers confirmed the EFA model, using the same sample with which the EFA was conducted, using AMOS $24 .{ }^{26}$ As in the EFA model, the CFA yielded the same three factors, but one item was deleted in factor 2 (Item 16: Medical professionals should demonstrate their willingness to make sacrifices and contributions toward the interests of patients and society) because its factor loading was below the benchmark of 0.70 . Hence, the CFA model resulted in 20 items (see Appendix): "personal integrity and accountability" (9 items; factor loadings: 0.723-0.819), "sensitivity to others" (5 items; factor loadings: 0.764-0.900), and "medical professional competence" (6 items; factor loadings: 0.722-0.825). All factor loadings met the well-defined factor structure, whose benchmark value was greater than $0.70 .^{38}$ The three-factor CFA model for the twenty items is shown in Figure 2.

\section{Goodness of Fit of the CFA Model for the HPAS-HSP Scale}

To further verify the goodness of fit of the CFA model, the study used a variety of indices to compare the EFA and CFA model, including a $\chi^{2} / \mathrm{df}$ ratio, CFI, TLI, and RMSEA. According to Byrne, ${ }^{31}$ to show an acceptable model fit, a $\chi^{2} / \mathrm{df}$ ratio value should be less than 2 , with $p$ values $>0.05$. Regarding the CFI, a CFI greater than 0.90 can be considered acceptable, and a CFI greater than 0.95 is considered excellent. ${ }^{32,33}$ A TLI greater than 0.90 is regarded as an acceptable model fit, and a TLI greater than 0.95 is considered excellent. ${ }^{34,35}$ An RMSEA index below 


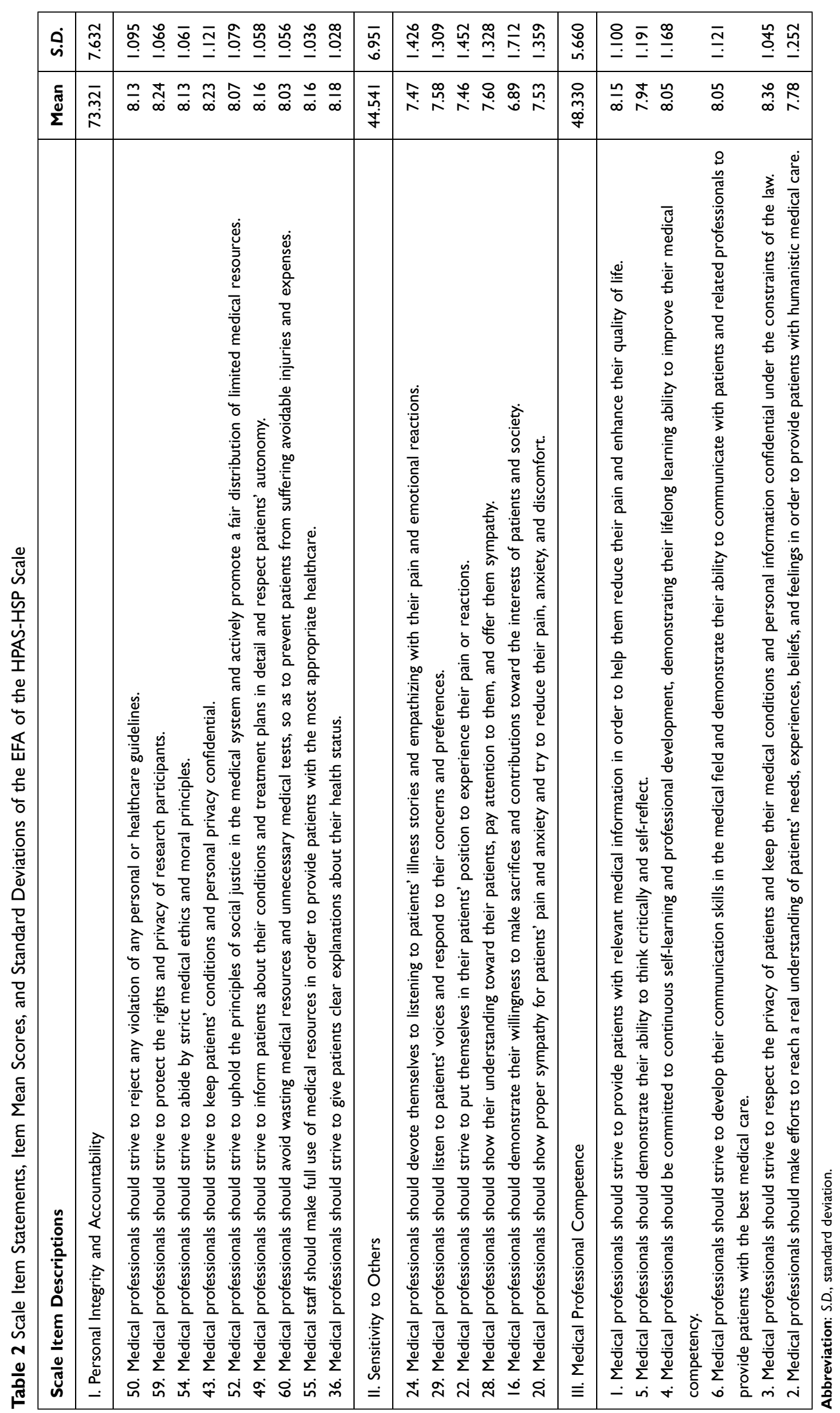




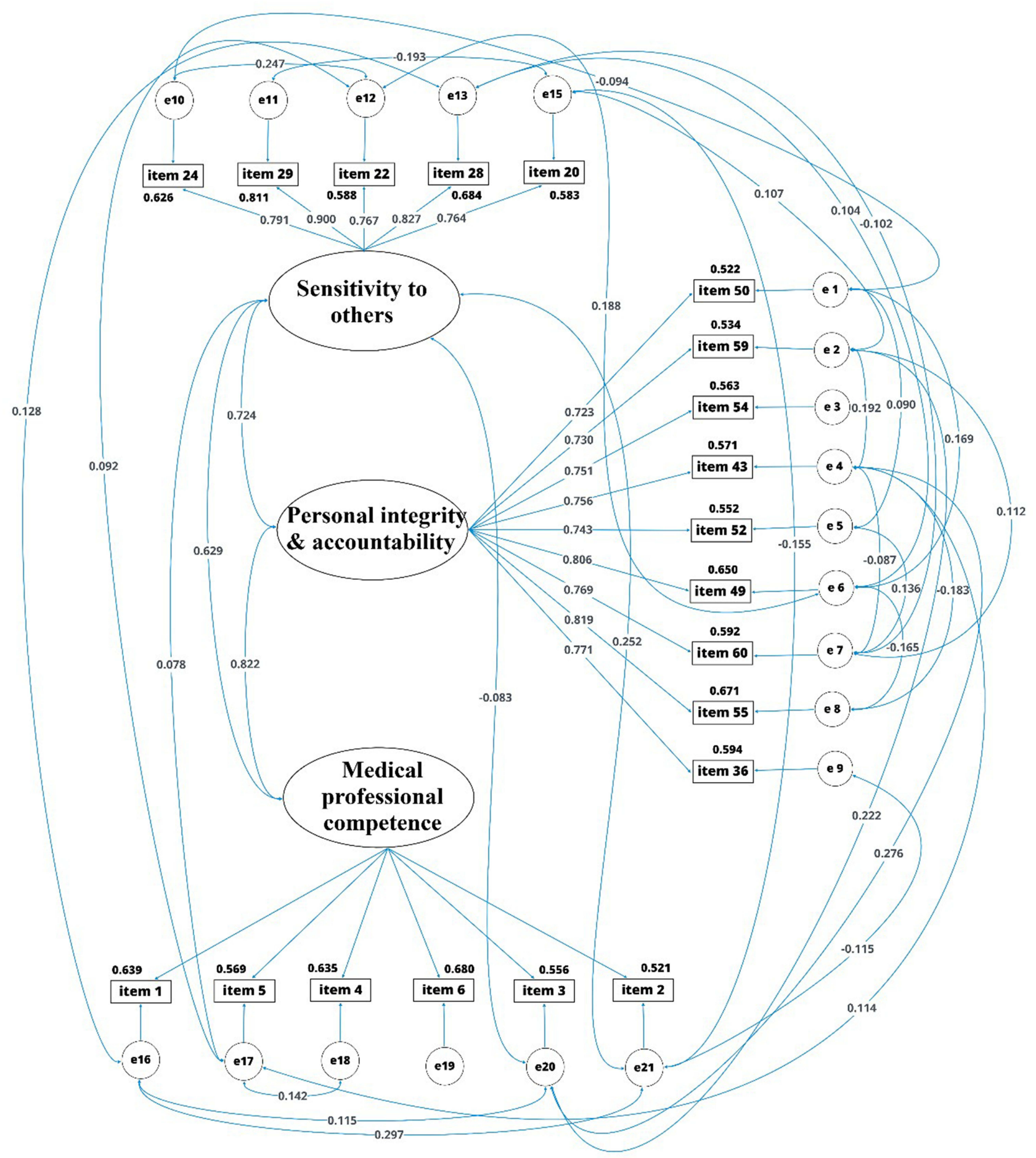

Figure 2 CFA for the HPAS-HSP scale.

0.08 is considered acceptable, and an RMSEA index below 0.05 is considered excellent. ${ }^{36}$ As shown in Table 3, in the EFA model, the $\chi^{2} / \mathrm{df}$ ratio is 3.474 ( $p=$ 0.000 ), CFI is 0.955 , TLI is 0.950 , RMSEA is 0.058 , and CI for RMSEA is [0.054, 0.063]. The researchers later connected the two variables with high covariance and modified the indices until all indices reached goodness of fit $^{30-36}$ the CFA model is shown in Figure 2. Regarding the modification indices in the CFA model, as shown in Table 4 , the $\chi^{2} / \mathrm{df}$ ratio is $1.130(p=0.140 ; p>0.05)$, CFI is 0.998 , TLI is 0.998 , RMSEA is 0.013 , and CI for RMSEA is $[0.000,0.023]$. 
Table 3 Goodness-of-Fit Indices for the EFA and CFA for the HPAS-HSP Scale

\begin{tabular}{|l|c|c|c|c|c|c|}
\hline & $\chi^{2}$ /df & $\mathbf{p}$ & CFI & TLI & RMSEA & 90\% RMSEA CI \\
\hline EFA & 3.474 & 0.000 & 0.955 & 0.950 & 0.058 & {$[0.054,0.063]$} \\
CFA & 1.130 & 0.140 & 0.998 & 0.998 & 0.013 & {$[0.000,0.023]$} \\
Improvement & & $p>0.05$ & 0.043 & 0.048 & -0.045 & \\
\hline
\end{tabular}

Note: $\mathrm{n}=725$.

Abbreviations: $\chi^{2}$, Chi-square; df, degree of freedom; CFI, comparative fit index; TLI, Tucker Lewis index; RMSEA, root mean square error of approximation; Cl, Confidential Index.

Table 4 Convergent Validities and Cronbach's Alphas: Examination of the CFA for the HPAS-HSP Scale

\begin{tabular}{|l|c|c|c|}
\hline AVE and Composite Alpha Factor & AVE & Cronbach's Alpha & Composite Alpha \\
\hline I. Personal Integrity and Accountability & 0.583 & 0.927 & 0.926 \\
2. Sensibility to Others & 0.658 & 0.904 & 0.906 \\
3. Medical Professional Competence & 0.599 & 0.904 & 0.900 \\
\hline
\end{tabular}

\section{Reliability}

For the CFA model, the Cronbach's alphas for the three subscales were 0.927 ("personal integrity and accountability"), 0.904 ("sensitivity to others"), and 0.904 ("medical professional competence"). The researchers further calculated composite reliabilities (see Table 4) to examine the scale's stability and internal consistency. The derived composite reliability coefficients were $0.926,0.906$, and 0.900 , which are all higher than Hair et $\mathrm{al}^{30}$ cutoff value of 0.70 . Hence, the HPAS-HSP scale has proved its excellent reliabilities in assessing participants' humanistic professional awareness.

\section{Convergent Validity}

To examine the convergent validity of the scale, the AVE (average variance extracted) values of each factor were calculated and compared to its correlation with other factors, using composite reliability values. ${ }^{30,39}$ Convergent validity would be determined if the AVE of the factor was at least 0.50 and smaller than its corresponding composite alpha values. The AVE values for the three subscales are, in fact, greater than 0.50 (see Table 4): 0.583 ("personal integrity and accountability"), 0.658 ("sensitivity to others"), and 0.599 ("medical professional competence"); the corresponding composite reliabilities are 0.926, 0.906, and 0.900, respectively. Considering that the AVE values of the subscales are not less than 0.50 and are smaller than the composite values, ${ }^{30,39}$ the HPASHSP scale has demonstrated its convergent validity.

\section{Discriminant Validity}

To confirm the discriminant validity of the HPAS-HSP scale, the square root values of the AVE ( $\sqrt{\text { AVE}}$ ) were calculated and compared to the corresponding Pearson's Correlation Coefficient (as Pearson's $r$ ) between factors. ${ }^{40}$ Discriminant validity is demonstrated when the $\sqrt{A V E}$ of the factor is higher than its Pearson's $r$ with other factors. $^{30,39}$ As shown in Table 5, the discriminant validity was proved between the factors of "personal integrity and accountability" and "sensitivity to others" ( $\sqrt{\mathrm{AVE}}=0.764$ and 0.811 , respectively; $r=0.664)$, "personal integrity and accountability" and "medical professional competence" ( $\sqrt{ } \mathrm{AVE}=0.764$ and 0.774 , respectively; $r=0.748)$, and "sensitivity to others" and "medical professional competence" ( $\sqrt{ } \mathrm{AVE}=0.811$ and 0.774 , respectively; $r=0.604$ ).

The results of the validities and reliabilities have demonstrated the feasibility of using the HPAS-HSP as a measure to assess healthcare students' and providers' humanistic professional awareness.

\section{Discussion}

This study intended to develop an instrument to measure humanistic professional awareness so that it could be used as a reference for forming relevant curricula, programs, courses, or on-the-job training to enhance humanistic professional awareness. Mainly based on Slavec and

Table 5 Discriminant Validities: Examination of the CFA for the HPAS-HSP Scale

\begin{tabular}{|l|c|c|c|}
\hline Factor & I & $\mathbf{2}$ & $\mathbf{3}$ \\
\hline I. Personal Integrity and & $\mathbf{0 . 7 6 4}$ & & \\
Accountability & & & \\
2. Sensibility to Others & $0.664^{* *}$ & $\mathbf{0 . 8 1}$ & \\
3. Medical Professional Competence & $0.748^{* *}$ & $0.604^{* *}$ & $\mathbf{0 . 7 7 4}$ \\
\hline
\end{tabular}

Notes: The values shown in bold are the square root of AVE ( $\operatorname{AVE}) * * p<0.001$. 
Drnovšek $^{22}$ ten steps in three phases, after the literature review and interviews for item pool generation, the study called up expert panel discussion to screen out inappropriate items and classified the collected items into three categories as a priori hypothetical model, which were: "personal integrity and accountability," "sensitivity to others," and "medical professional competence." The content validity was confirmed through panel discussions.

While testing the psychometric properties of the HPAS-HSP scale, the researchers combined the techniques of EFA and CFA, using EFA to examine the latent variable structure of the dataset and then conducting CFA to verify whether the dataset was suitable for the model. ${ }^{41,42}$ Initially, the panel sorted the collected items into three categories as an a priori hypothetical model. The researchers could have conducted the CFA alone; however, in order to validate the a priori hypothetical model, the researchers instead took a more conservative approach by conducting the EFA before the CFA. ${ }^{41,42}$

The application of EFA resulted in 21 items in three factors, explaining $66.221 \%$ of the variance: "personal integrity and accountability" (9 items), "sensitivity to others" (6 items), and "medical professional competence" (6 items). The subscale means showed that the respondents scored the highest on the "personal integrity and accountability" subscale (mean = $8.147 ; 73.321 \div 9=8.147$ ), followed by "medical professional competence" ( mean $=8.055)$. The participants scored the lowest on "sensitivity to others" (mean $=7.424)$. This subscale mean showed that these respondents think that medical professionals should strive to reject any violation of any personal or healthcare guidelines and also protect the rights and privacy of research participants. Also, they believe in striving to provide patients with relevant medical information in order to help them reduce their pain and improve their quality of life. Moreover, they support the necessity of demonstrating their ability to think critically and self-reflect. Relatively, compared to humanistic professional awareness in connection to "personal integrity and accountability" and "medical professional competence," these respondents focus less attention on "sensitivity to others"; for instance, they place less effort on listening to patients' voices and responding to their concerns and preferences. The EFA model revealed that the factor loading ranged from 0.722 to 0.830 , all greater than the cutoff value, 0.70, of a well-defined factor structure, thus demonstrating evidence for the construct validity of the HPAS-HSP scale. ${ }^{30}$ Also, Pearson's correlation coefficients (Pearson's $r$ ) of the HPAS-HSP scale all range between 0.604 and 0.748 . According to Munro, ${ }^{43}$ Pearson's $r$ falling in the range between
0.00 and 0.25 indicates a very low correlation; a Pearson's $r$ between 0.26 and 0.49 indicates a low correlation, a Pearson's $r$ between 0.50 and 0.69 indicates a moderate correlation, a Pearson's $r$ between 0.70 and 0.89 indicates a strong correlation, and a Pearson's $r$ between 0.9 and 1.0 indicates a very strong correlation. Hence, the Pearson's correlation results derived in the study revealed a moderate and strong correlation between two related factors. The highest Pearson's $r$ among the HPAS-HP scores was between "personal integrity and accountability" and "medical professional competence" ( $r=$ 0.748; $p<0.001$ ), and the lowest correlation was between "sensitivity to others" and "medical professional competence" $(r=0.604 ; \mathrm{p}<0.001)$.

The researchers further used the CFA statistical technique, with AMOS 24.0, to examine the factorial validity of the EFA model for the HPAS-HSP scale. ${ }^{44}$ After the CFA statistical analysis, one item, item 16 in "sensitivity to others," was deleted, resulting in a 20 -item CFA model. The factor loadings for each item statement in the CFA model ranged between 0.722 and 0.900 , indicating that the factor indicators in the model are adequate. The Cronbach's alphas and composite alphas also demonstrated good construct validity in terms of Hair et al criterion. ${ }^{30}$ Compared with the HPAN measurement tool, $^{45}$ an instrument evaluating humanistic practice ability of nursing, whose Cronbach's alphas for the subscales of the HPAN ranged from $0.782-0.867$, the Cronbach's alphas for the three subscales of the HPAS-HP were all above 0.90 . Hence, the developed HPAS-HSP scale has demonstrated its better reliabilities in assessing participants' humanistic professional awareness. Using modification indices to examine the model's goodness of fit, ${ }^{37}$ the varied fit indices, in terms of the $\chi^{2} / \mathrm{df}$ ratio, CFI, TLI, and RMSEA, all demonstrated goodness of fit. The $\chi^{2} / \mathrm{df}$ ratio value, with a value less than 2 and $p$ values $>0.05$, indicates an acceptable model fit. ${ }^{31}$ The CFI index and TFI index, with values greater than 0.95 , indicates an excellent model fit. ${ }^{32-35}$ The RMSEA index, with a value less than 0.05 , also demonstrates an excellent model fit. ${ }^{36}$ Compared with the goodness-of-fit indices in the EFA model, the indices in the CFA model have proved to have better goodness of fit, with an increase of 0.043 and 0.048 in CFI and TLI, respectively, a decrease of 0.045 in RMSEA, and a decrease of 2.344 in the $\chi^{2}$ df ratio value, with the $p$ value becoming insignificant $(p>0.05$; see Table 3$)$.

The convergent validities were clearly established, in terms of Hair et al and Malhorta studies, with all of the AVE values of "personal integrity and accountability, "sensitivity to others," and "medical professional competence" greater than the benchmark value of 0.50 and less than the corresponding 
composite values. ${ }^{30,39}$ The discriminant validities were also established, in terms of Hair et $\mathrm{al}^{30}$ and Fornell and Larcker criteria, ${ }^{46}$ as all the $\sqrt{ }$ AVE values of the factor are higher than the correlation coefficients $(r)$ with other factors between the factors of "personal integrity and accountability" and "sensitivity to others," "personal integrity and accountability" and "medical professional competence," and "sensitivity to others" and "medical professional competence."

The factor structure and the varied psychometric properties in assessment, in terms of internal consistency, convergent validities, discriminant validities, goodness-of-fit indices, and so on, demonstrate that the HPAS-HSP scale can be a valid instrument to assess humanistic professional awareness.

\section{Conclusion}

This study aimed to develop an instrument measuring healthcare students' and providers' humanistic professional awareness, in terms of Slavec and Drnovšek's ten steps and three phases in scale development and EFA and CFA statistical analysis. The study provided evidence that the HPAS-HSP scale has been proven to have a good factor construct, with good face validity and psychometric properties; hence, it has been proven to be an appropriate instrument in measuring students' and providers' humanistic professional awareness. Further studies may use the instrument to design relevant curricula, programs, courses, and on-the-job training to enhance healthcare students' and providers' humanistic professional awareness.

\section{Acknowledgments}

The researchers thank all the participants in the study.

\section{Disclosure}

The authors declare no conflicts of interest for this work.

\section{References}

1. Batistatou A, Doulis EA, Tiniakos D, Anogiannaki A, Charalabopoulos K. The introduction of medical humanities in the undergraduate curriculum of Greek medical schools: challenge and necessity. Hippocratia. 2010;14(4):241-243.

2. Institute for Alternative Futures (IAF). Patient-Centered Care 2015: Scenarios, Vision, Goals, and Next Steps. Alexandria, VA: Picker Institute; 2004.

3. Stern DT, Cohen JJ, Bruder A, Packer B, Sole A. Teaching humanism. Perspect Biol Med. 2008;51(4):495-507. doi:10.1353/pbm.0.0059

4. Tsai TC, Lin CH, Harasym PH. Students' perception on medical professionalism: the psychometric perspective. Med Teach. 2007;29 (2):128-134. doi:10.1080/01421590701310889
5. Wong YF, Lin SJ, Cheng HC, et al. The formation and performance of medical humanities by interns in a clinical setting. Tzu Chi Med J. 2012;24(1):5-11. doi:10.1016/j.tcmj.2011.11.004

6. Moore AR. Medical humanities a new medical adventure. $N$ Engl $J$ Med. 1976;295(26):1479-1480. doi:10.1056/NEJM1976122329 52610

7. McLellan MF. Literature and medicine: physician-writers. Lancet. 1997;349(9051):564-567. doi:10.1016/S0140-6736(97)80120-1

8. Kang WS, Yim SH, Harris I, Na H, Kim PM. Students' perspectives about the medical humanities curriculum at the Catholic University of Korea. Int J Med Educ. 2013;4:207-213. doi:10.5116/ijme.524f. d329

9. Coutts LC, Rogers JC. Humanism: is its evaluation captured in commonly used performance measures? Teach Learn Med. 2000;12 (1):28-32. doi:10.1207/S15328015TLM1201_5

10. Ousager J, Johannessen H. Humanities in undergraduate medical education: a literature review. Acad Med. 2010;85(6):988-998. doi:10.1097/ACM.0b013e3181dd226b

11. Macnaughton J. The humanities in medical education: context, outcomes and structures. Med Humanit. 2000;26(1):23-30. doi:10.1136/ mh.26.1.23

12. Buyx AM, Maxwell B, Schone-Seifert B. Challenges of educating for medical professionalism: who should step up to the line? Med Educ. 2008;42:758-764. doi:10.1111/j.1365-2923.2008.03112.x

13. Ludmerer KM. Instilling professionalism in medical education. JAMA. 1999;282:881-882. doi:10.1001/jama.282.9.881

14. Chou CM, Kellom K, Shea JA. Attitudes and habits of highly humanistic physicians. Acad Med. 2014;89(9):1252-1258. doi:10.1097/ACM.0000000000000405

15. Cohen JJ. Viewpoint: linking professionalism to humanism: what it means, why it matters. Acad Med. 2007;82(11):1029-1032. doi:10.1097/01.ACM.0000285307.17430.74

16. Weissmann PF, Branch WT, Gracey CF, Haidet P, Frankel RM. Role modeling humanistic behavior: learning bedside manner from the experts. Acad Med. 2006;81(7):661-667. doi:10.1097/01. ACM.0000232423.81299.fe

17. Fahrenwald NL, Bassett SD, Tschetter L, Carson PP, Whtte L, Winterboer VJ. Teaching core nursing values. J Prof Nurs. 2005;21 (1):46-51. doi:10.1016/j.profnurs.2004.11.001

18. Tonges M, Ray J. Translating caring theory into practice: the Carolina care model. J Nurs Adm. 2011;41(9):374-381. doi:10.1097/ NNA.0b013e31822a732c

19. Misch DA. Evaluating physicians' professionalism and humanism: the case for humanism "Connoisseurs.". Acad Med. 2002;77:489-495. doi:10.1097/00001888-200206000-00004

20. Bellini LM, Shea JA. Mood change and empathy decline persist during three years of internal medicine training. Acad Med. 2005;80:164-167. doi:10.1097/00001888-200502000-00013

21. Lee WN, Langiulli M, Mumtaz A, Peterson SJ. A comparison of humanistic qualities among medical students, residents, and faculty physicians in internal medicine. Heart Dis. 2003;5:380-383. doi:10.1097/01.hdx.0000098641.24830.86

22. Slavec A, Drnovšek M. Perspective on scale development in entrepreneurship research. Econ Business Rev. 2012;14(1):39-62. doi: $10.15458 / 2335-4216.1203$

23. TSA. Research ethics framework of society institute in Taiwan. Available from: http://proj3.sinica.edu.tw/ tsa/modules/tadnews/ index.php?nsn=43. Accessed November 26, 2016.

24. IBM Corp. IBM SPSS Statistics for Windows, Version 24.0. Armonk, NY: IBM Corp; 2016.

25. Tabachnick BG, Fidell LS. Using Multivariate Statistics. 5th ed. Upper Saddle River, NJ: Pearson Allyn \& Bacon; 2007.

26. Arbuckle JL. IBM SPSS Amos 24 User's Guide. New York, NY: IBM; 2015.

27. Kaiser HF. An index of factorial simplicity. Psychometrika. 1974;39:31-36. doi:10.1007/BF02291575 
28. Kaiser HF. The application of electronic computers to factor analysis. Educ Psychol Meas. 1960;20:141-151. doi:10.1177/0013164 46002000116

29. Bartlett MS. A further note on tests of significance in factor analysis. Br J Psychol. 1951;4:1-2.

30. Hair J, Black W, Babin B, Anderson R. Multivariate Data Analysis. 7th ed. Upper Saddle River, NJ: Prentice-Hall; 2010.

31. Byrne BM. Structural equation modeling with AMOS, EQS, and LISREL: comparative approaches to testing for the factorial validity of a measuring instrument. Int $J$ Testing. 2001;1(1):55-86. doi:10.1207/S15327574IJT0101_4

32. Bentler PM. Comparative fit indexes in structural models. Psychol Bull. 1990;107(2):238-246. doi:10.1037/0033-2909.107.2.238

33. Sharma S, Mukherjee S, Kumar A, Dillon WR. A simulation study to investigate the use of cutoff values for assessing model fit in covariance structure models. J Bus Res. 2005;58(7):935-943. doi:10.1016/ j.jbusres.2003.10.007

34. Ma Z. Application of structural equation modeling to evaluate customer satisfaction in the China internet bank sector. Proceedings of the International Conference on Instrumentation, Measurement, Circuits and Systems (ICIMCS 2011), Hong Kong, China, 12 13 December 2011. ASME International; 2011:975-978.

35. Schermelleh-Engel K, Moosbrugger H. Evaluating the fit of structural equation models: tests of significance and descriptive goodness-of-fit measures. Methods Psychol Res Online. 2003;8(2):23-74.

36. $\mathrm{Hu} \mathrm{L}$, Bentler PM. Cutoff criteria for fit indexes in covariance structure analysis: conventional criteria versus new alternatives. Struct Equ Modeling. 1999;6(1):1-55. doi:10.1080/107055 19909540118

37. Churchill GA Jr. A paradigm for developing better measures of marketing constructs. J Marketing Res. 1979;16(1):64-73. doi:10.1177/002224377901600110
38. Bahkia AS, Awang Z, Afthanorhan A, Ghazali PL, Foziah H. Exploratory factor analysis on occupational stress in context of Malaysian sewerage operations. Paper presented at the 4th Innovation and Analytics Conference \& Exhibition; 2019.

39. Malhotra NK. Pesquisa De Marketing: Uma Orientação Aplicada [Marketing Research: An Applied Guidance]. 6th ed. São Paulo, Brazil: Bookman; 2011. Portuguese.

40. Gefen D, Straub D, Boudreau MC. Structural equation modeling and regression: guidelines for research practice. Commun AIS. 2000;4 (7):1-78

41. Hurley AE, Scandura TA, Schriesheim CA, et al. Exploratory and confirmatory factor analysis: guidelines, issues, and alternatives. J Organ Behav. 1997;18(6):667-683. doi:10.1002/(SICI)1099-1379(199711)18:6<667::AID-JOB874>3.0.CO;2-T

42. Menezes MS, Gusmão MM, Santana RM, et al. Translation, transcultural adaptation, and validation of the role-modeling cost-conscious behaviors scale. BMC Med Educ. 2019;19(1):151. doi:10.1186/s12909-019-1587-x

43. Munro BH. Statistical Methods for Health Care Research. Philadelphia, PA: Lippincott Williams \& Wilkins; 2005.

44. Gomez R, Fisher JW. Domains of spiritual well-being and development and validation of the spiritual well-being questionnaire. Pers Individ Dif. 2004;35(8):1975-1991. doi:10.1016/S0191-8869(03) 00045-X

45. Wang HF, Liu L, Zhang JH, Chen Y. Development of a scale for evaluating humanistic practice ability of nursing. China Higher Med Educ. 2015;1:28-29.

46. Fornell C, Larcker DF. Evaluating structural equation models with unobservable variables and measurement error. J Mark Res. 1981;18 (1):39. doi:10.1177/002224378101800104
Journal of Multidisciplinary Healthcare

\section{Publish your work in this journal}

The Journal of Multidisciplinary Healthcare is an international, peerreviewed open-access journal that aims to represent and publish research in healthcare areas delivered by practitioners of different disciplines. This includes studies and reviews conducted by multidisciplinary teams as well as research which evaluates the results or conduct of such teams or healthcare processes in general. The journal covers a very wide range of areas and welcomes submissions from practitioners at all levels, from all over the world. The manuscript management system is completely online and includes a very quick and fair peer-review system. Visit http://www.dovepress.com/testimonials. php to read real quotes from published authors. 